\title{
Educação Física Escolar - uma percepção das(os) ex- discentes de uma escola estadual norte mineira
}

\author{
School Physical Education - a perception of ex-students from a north \\ mining state school
}

\section{Educación Física Escolar: una percepción de ex estudiantes de una escuela estatal de north mining}

Andréia de Fátima Vieira Silva1; Carla Chagas Ramalho²

\section{RESUMO}

Este trabalho visa investigar qual a percepção da Educação Física escolar de ex-discentes de uma escola pública do Norte de Minas Gerais. Como metodologia, utilizamos a pesquisa descritiva, de corte transversal e abordagem qualitativa dos dados. Utilizamos como instrumento de investigação a pesquisa bibliográfica e de campo, sendo que, nesta última, foram aplicados questionários on-line, preparados pelas pesquisadoras, com 15 (quinze) perguntas. A população foi composta por 11 (onze) ex-alunos(as) de uma mesma escola, no Norte de Minas Gerais, formados(as) entre os anos de 2016, 2017, 2018 e 2019. Concluímos que houve uma diferenciação das respostas correspondentes aos(as) formandos(as) de 2019 em relação aos do ano de 2016. Assim, refletimos como a diversificação de conteúdos da Educação Física na Educação Básica auxilia numa percepção mais abrangente do papel da Educação Física escolar; também, apontamos que não devemos negligenciar a função das secretarias de educação na formação continuada das(os) docentes.

Palavras-chave: Educação Física Escolar; Currículo; Prática pedagógica.

\begin{abstract}
This work aims to investigate the perception of school physical education of former students of a public school in the North of Minas Gerais. As a methodology, we used descriptive, cross-sectional research and a qualitative approach to the data. We used as an instrument of investigation the bibliographic and field research, and, in the latter, online questionnaires were applied, prepared by the researchers, with 15 (fifteen) questions. The population was composed of 11 (eleven) alumni(s) from the same school, in the North of Minas Gerais, formed (as) between the years 2016, 2017, 2018 and 2019. We conclude that there was a differentiation of the answers corresponding to the trainees(s) of 2019 in relation to those of the year 2016. Thus, we reflect how the diversification of Physical Education contents in Basic Education aids in a broader perception of the role of Physical Education in schools; also, we point out that we should not neglect the function of education departments in the continuing formation of(s) teachers.
\end{abstract}

Keywords: School Physical Education; Curriculum; Pedagogical practice.

\section{RESUMEN}

Este trabajo busca investigar cuál es la percepción de la Educación Física escolar de ex alumnos de una escuela pública del Norte de Minas Gerais. Como metodología, utilizamos la investigación descriptiva, de corte transversal y enfoque cualitativo de los datos. Utilizamos como instrumento de investigación la investigación bibliográfica y de campo, siendo que, en esta última, fueron aplicados cuestionarios online, preparados por las

\footnotetext{
${ }^{1}$ Licenciada em Educação Física pela Universidade Estadual de Montes Claros, Montes Claros/MG - Brasil.

${ }^{2}$ Graduada em Educação Física, Especialista em Gênero e Sexualidade, Mestre em Educação (UFRJ) e Professora do Departamento de Educação Física e Desporto da Universidade Estadual de Montes Claros, Brasil.
} 
investigadoras, con 15 (quince) preguntas. La población fue compuesta por 11 (once) exalumnos(as) de una misma escuela, en el Norte de Minas Gerais, formados(as) entre los años de 2016, 2017, 2018 y 2019. Concluimos que hubo una diferenciación de las respuestas correspondientes a los(as) graduados(as) de 2019 en relación a los del año 2016. Así, reflexionamos cómo la diversificación de contenidos de la Educación Física en la Educación Básica auxilia en una percepción más amplia del papel de la Educación Física escolar; también, apuntamos que no debemos descuidar la función de las secretarías de educación en la formación continuada de las(los) docentes.

Palabras clave: Educación Física Escolar; Plan de estudios; Práctica pedagógica.

\section{INTRODUÇÃO}

O movimento humano está inserido nas mais diversas atividades do cotidiano de todos os sujeitos, inclusive no âmbito da cultura, e a Educação Física é uma disciplina escolar que utiliza o movimento como uma das suas principais ferramentas de trabalho. De acordo coma Base Nacional Comum Curricular - BNCC (2018), ela é uma disciplina capaz de tematizar as práticas corporais nas mais diversas formas de codificação e significação social, representando as possibilidades do ser humano de se expressar corporalmente, nos diferentes grupos sociais, por todo o decorrer da história.

Pode-se dizer, segundo González (2016, p. 4), que professoras e professores daquele componente curricular atuam de três formas: (a) práticas tradicionais; (b) o abandono do trabalho docente (ou desinvestimento pedagógico); e (c) práticas inovadoras. As práticas tradicionais são as formas de trabalho em que a centralidade está no ensino do esporte de rendimento, ou mesmo na vertente de aptidão física e saúde. O abandono do trabalho docente é o que, no meio, se chama de "rola bola" ou a "não aula", que é quando o professor ou a professora não possui pretensão de ensinar os conteúdos científicos inerentes à Educação Física, mas de ocupar o tempo dos(as) alunos e alunas. Por fim, as práticas inovadoras são as práticas docentes empenhadas em desenvolver os conteúdos específicos da disciplina, pautados nos parâmetros do componente curricular (GONZÁLEZ, 2016). A partir dessas definições, nos amparamos nas práticas inovadoras para a análise de qual percepção sobre a Educação Física escolar predomina entre os(as) alunos(as) que já cursaram e se formaram na Educação Básica.

Julgamos relevante investigar como atualmente os(as) ex-alunos(as) de uma Escola no Norte de Minas Gerais tiveram a vivência da Educação Física escolar durante toda a Educação Básica e como veem essa disciplina; analisar o valor que é dado a ela, e como o ensino transmitido influencia nessa importância. Assim, este estudo justifica-se por servir para as suposições de como a Educação Física vem sendo trabalhada, atualmente, naquele local, e a influência que isso pode causar na visão dos(as) alunos(as) e de toda a comunidade escolar. Esta pesquisa pode, ainda, servir para os(as) demais docentes da área, até mesmo de outras localidades, como uma forma de reflexão sobre/para sua prática docente.

Por isso, com o intuito de investigação, o problema deste trabalho define-se, então, em "qual a percepção dos(as) ex-alunos(as) de uma Escola do Norte de Minas Gerais acerca do significado da Educação Física Escolar, após sua vivência na Educação Básica". Temos como objetivo central investigar qual o entendimento dos(as) ex-alunos(as) de uma Escola do Norte de Minas Gerais acerca do significado da Educação Física escolar, após sua vivência na Educação Básica. 


\section{A IMPORTÂNCIA DA PRÁTICA PEDAGÓGICA}

A prática pedagógica é definida como uma prática com dimensão social, a qual deve ser delimitada por objetivos, conhecimentos e finalidades, introduzidas num determinado contexto social, sempre interligando teoria - prática, em que é papel do(a) professor(a) a busca pelas condições necessárias para a realização de tal (VEIGA, 1989). Bracht apud Medina (1983) define a prática pedagógica dentro da Educação Física como a intervenção que o(a) docente desse componente curricular faz dentro das escolas onde atuam.

O professor e a professora, antes de tudo, devem pensar sobre sua postura em sala de aula, e como ele(ela), sendo espelho para os(as) alunos(as), influenciará na vida destes(as) e em sua tomada de decisão ao longo dos anos. Haidt (1994, p. 57) corrobora essa ideia, quando afirma que "cabe ao professor, durante sua intervenção em sala de aula e por meio de sua interação com a classe, ajudar o(a) aluno(a) a transformar sua curiosidade em esforço cognitivo e a passar de um conhecimento confuso, sincrético, fragmentado, a um saber organizado e preciso". Ou seja, o(a) docente deve fomentar ao máximo a curiosidade nos(as) alunos(as), para que, assim, consigam cada vez mais buscar conhecimento a partir de si próprio, sendo um(a) mediador(a) do conhecimento, e não um(a) adestrador(a), como afirmam Moura, Souza e Carvalho (2012, p.8):

O professor deve envolver afetivamente os seus alunos, de forma que sua ação pedagógica influencie a diversidade e traga para o estudante o grau de envolvimento das relações humanas e sócias. Devem haver conflitos, mas sempre servindo como oportunidade de aprendizagem, sendo compreendido como algo natural das relações humanas, tendo o professor apenas como mediador desse processo e não como um adestrador.

Ainda de acordo com Moura, Souza e Carvalho (2012), a prática docente deve contribuir para a formação dos(as) alunos(as) como seres críticos e reflexivos, capazes de pensarem e atuarem no meio em que vivem, levando em consideração as questões de desigualdades existentes nesse meio. Isto é, cabe ao/a professor/a possibilitar espaços de experiências significativas, a fim de contribuir para a formação de um ser humano ativo, crítico e participativo, capaz de refletir e se posicionar em meio às diversas situações do cotidiano, sejam elas positivas ou negativas. Corroborando o pensamento, Haidt (1994) afirma que o professor e a professora têm, como sua principal função, construir nesse aluno(a) esta pessoa ativa, induzindo-o a se expressar tanto física quanto cognitivamente.

Portanto, é importante que o(a) professor(a) reflita sobre sua prática docente, e como esta vem influenciando na vida dos(as) alunos(as); ou, ainda, se ela tem sido uma prática que soma na vida destes, de diferentes formas e em distintos campos de conhecimento, pois, de acordo com Melo (2006), a Educação Física - através de suas práticas pedagógicas - deve oferecer aos alunos e alunas uma aprendizagem que garanta um melhor entendimento de suas práticas corporais e de sua cultura corporal ${ }^{3}$.

\footnotetext{
${ }^{3} \mathrm{~A}$ fragilidade de recursos biológicos fez com que os seres humanos buscassem suprir as insuficiências com criações que tornassem os movimentos mais eficazes, seja por razões "militares", relativas ao domínio e uso de espaço, seja por razões econômicas, que dizem respeito às tecnologias de caça, pesca e agricultura, seja por razões religiosas, que tangem aos rituais e festas ou por razões apenas lúdicas. Derivaram daí inúmeros conhecimentos e representações que se transformaram ao longo do tempo, tendo ressignificadas as suas intencionalidades e formas de expressão, e constituem o que se pode chamar de cultura corporal (BRASIL, 1997b, p. 23).
} 


\section{CONTEÚDOS DA EDUCAÇÃO FÍSICA ESCOLAR}

A necessidade da sistematização dos conteúdos dentro da Educação Física escolar é relevante para uma organização didática de como os conhecimentos pedagógicos devem ser trabalhados com os(as) alunos(as), levando em consideração que a aprendizagem é um processo gradativo e que os(as) estudantes não se apropriam do um conhecimento de uma única vez (MELLO, 2006). Com isso, neste tópico, analisaremos os conteúdos destinados à Educação Física escolar ao longo da Educação Básica, considerando o período escolar dos(as) alunos(as) que participaram desta pesquisa.

Assim, serão pertinentes à nossa análise os seguintes documentos: Parâmetros Curriculares Nacionais (PCN); Currículo Básico Comum (CBC), documento norteador próprio do estado de Minas Gerais. A escolha se justifica pelo fato de serem documentos norteadores em nível nacional e estadual, respectivamente; e pelo fato de querermos analisar quais os conteúdos deveriam ter sido (ou foram) desenvolvidos no período escolar das pessoas pesquisadas.

Para dar início, definimos, então, o que vem a ser conteúdo, segundo Darido e Souza Júnior (2007, p. 15):

[...] quando nos referimos a conteúdos estamos englobando conceitos, ideias, fatos, processos, princípios, leis científicas, regras, habilidades cognoscitivas, modos de atividade, métodos de compreensão e aplicação, hábitos de estudos, de trabalho, de lazer e de convivência social, valores, convicções e atitudes.

É importante ressaltar que os conteúdos são distribuídos obedecendo ao grau de dificuldade referente a cada faixa etária, e estes vão aumentando gradativamente durante os anos. Rodrigues (1993) apud Pinto e Cunha (1998) comprovam essa ideia, quando diz que a Educação Física deve educar o(a) aluno(a) utilizando os movimentos como ferramenta de trabalho, partindo dos mais simples para os mais complexos, pois é através das mais variadas formas que se consolidam modos de ensinar esse mesmo(a) aluno(a). Veremos as referidas documentações a seguir.

\subsection{Parâmetros Curriculares Nacionais (PCN)}

Os PCN foram desenvolvidos como um referencial de qualidade para a educação em todo o país, tendo como intuito orientar os professores e professoras, e garantir a eficiência da aplicabilidade de conteúdos em todo o território nacional, levando em consideração as discussões, pesquisas e recomendações, e a participação de professores(as), em especial, os mais isolados (BRASIL, 1997a).

Tanto os PCN dos anos iniciais e dos anos finais do Ensino Fundamental quanto o do Ensino Médio foram publicados, respectivamente, em 1997, 1998 e 1999, pelo Governo Federal, com o objetivo de "apontar metas de qualidade que ajudem o aluno a enfrentar o mundo atual como cidadão participativo, reflexivo e autônomo, conhecedor de seus direitos e deveres" (BRASIL, 1997b, p. 9).

Nos PCN de Educação Física, seus conteúdos são organizados em três blocos, que devem ser ministrados durante toda a Educação Básica, sendo eles: Esportes, Jogos, Lutas e Ginásticas; Atividades Rítmicas e Expressivas; além de Conhecimentos Sobre o Corpo (BRASIL, 1997b). De acordo com os parâmetros, todos os conteúdos da Educação Física possibilitam aos alunos(as) desenvolverem habilidades corporais, utilizando-se dessas práticas com diversas finalidades, como lazer, expressão de sentimentos, afetos e emoções (BRASIL, 1997b; BRASIL, 1998). 
Além disso, os PCN foram os primeiros documentos norteadores da educação em âmbito nacional, e, segundo Lavoura, Botura e Darido (2006), os parâmetros trouxeram em suas propostas temas transversais, que envolviam questões relevantes para o desenvolvimento das disciplinas dentro da Escola, como critérios de inclusão e as dimensões atitudinais, procedimentais e conceituais dos conteúdos que deveriam ser aplicados. Essa classificação das dimensões, propostas pelos PCN, é, na visão dos autores, de suma importância para o desenvolvimento do ensino da Educação Física. De acordo com Darido e Souza Júnior (2007, p. 17), a Educação Física "busca garantir o direito do aluno de saber porque ele está realizando este ou aquele movimento, isto é, quais conceitos estão ligados àqueles procedimentos (dimensão conceitual)".

Dessa forma, os PCN foram os primeiros documentos norteadores da Educação Física que se tornaram uma realidade, pois reforçavam a necessidade dos(as) alunos(as) de todo o país terem uma base comum de ensino, e, para isso, precisariam de um apontamento de como deveriam ser desenvolvidos o currículo e os conteúdos dentro da Escola, podendo, ainda, ser complementado em cada estado e Escola específica (BRASIL, 1997a).

\subsection{Currículo Básico Comum}

O Currículo Básico Comum (CBC) foi idealizado pela Secretaria de Educação do Estado de Minas Gerais (SEE-MG) no ano de 2005, constituindo-se em uma proposta curricular com o intuito de atender a todas as Escolas de rede pública deste estado. Após ser implantado em algumas Escolas de referência, contou com algumas modificações e foi distribuído em todos os colégios estaduais, no ano de 2007. No documento, a Educação Física tem seus conteúdos divididos em quatro eixos, a saber: Esporte; Jogos e Brincadeiras; Danças, Atividades rítmicas e movimentos expressivos; Ginásticas e suas manifestações (SEE, 2014a).

Na época da idealização desse documento norteador para o Estado de Minas Gerais, a educação tradicional estava sendo vista de forma obsoleta e desgastada, não contemplando a realidade vivida pela maioria dos(as) alunos(as) (CAUM; GALIETA, 2012) e, por esse motivo, o CBC seguiu as ideias dos PCN, surgindo como uma alternativa de renovar o ensino tradicional em âmbito estadual, com sugestões e propostas mais próximas da realidade do dia a dia dos(as) alunos e alunas, configurandose como de grande relevância para o desenvolvimento dos conteúdos no meio escolar.

Através dessa exposição, pode-se perceber que a Educação Física possui conteúdos bem delimitados, trazidos por documentos de âmbito nacional e estadual, os quais devem (ou deveriam) reger todo o processo de ensino-aprendizagem durante o período de escolarização, servindo de base para 0 desenvolvimento dos conteúdos em sala de aula.

\section{O PAPEL DA EDUCAÇÃO FÍSICA NA EDUCAÇÃO BÁSICA}

Durante muito tempo, a Educação Física, por ter sua origem em bases militares e médicas, e por servir para a manutenção do status quo, teve o seu fundamento de trabalho - o corpo e o movimento - atrelado apenas a aspectos fisiológicos e técnicos (BRASIL, 1997b). Nesse sentido, em meados do século passado, a Educação Física escolar esteve tão claramente vinculada ao Esporte, a ponto de ser confundida como uma prática esportiva, causando, assim, o que ficou conhecido como Esportivização da Educação Física Escolar (GONZÁLEZ; FENSTERSEIFER; LEMOS, 2007 apud GONZALEZ; FENSTERSEIFER, 2009). 
A Educação Física busca trabalhar com o "corpo em movimento" (BRASIL, 1997b), partindo da concepção de que a criança não aprende apenas lendo, escrevendo e falando, mas sim através do ato de movimentar-se e expressar-se corporalmente (SCHNEIDER, BUENO, 2005). Além de concordar com os autores anteriores, Lavoura, Botura e Darido (2006) afirmam, ainda, que o(a) estudante deve ser visto integralmente, levando em consideração todos os seus aspectos, tanto os motores quanto os cognitivos, sociais, afetivos e culturais.

A Educação Física, em todas as fases de ensino, é relevante para o desenvolvimento do(da) aluno(a) como um todo, atentando para os aspectos motores, psíquicos, sociais e afetivos. Nesse sentido, de acordo com Dezani et al. (2014), na Educação Infantil a Educação Física possui uma função significativa, pois é a partir do brincar que a criança passa a conhecer melhor o seu corpo, além de interagir com outros corpos, desenvolvendo-se não apenas fisicamente, mas também cognitivamente. Moura, Costa e Antunes (2016) partilham desse pensamento, quando dizem que é a partir do movimento corporal que a criança consegue se comunicar com as pessoas ao seu redor, se desenvolver, se expressar e aprender coisas novas, além de desenvolver sua autonomia e socialização. Ou seja, é a forma de linguagem da criança e, por isso, deve ser a base para a Educação Infantil.

Já nos anos iniciais do Ensino Fundamental, Brasil (1997b) expõe sobre a importância da Educação Física, visto que éa partir desta que os(as) alunos(as) têm mais possibilidades de desenvolver suas habilidades motoras, cognitivas, sociais e culturais, pois estão imersos no campo da Ginástica, Jogos e Brincadeiras, Lutas, Danças e Esportes, praticados com diferentes finalidades.

No meu entender, a Educação Física não é apenas educação do ou pelo movimento: é educação de corpo inteiro, entendendo-se, por isso, um corpo em relação com outros corpos e objetos, no espaço. Educar corporalmente uma pessoa não significa provê-la de movimentos qualitativamente melhores, apenas. Significa também educála para não se movimentar, sendo necessário para isso promover-se tensões e relaxamentos, fazer e não fazer (FREIRE, 2011, p. 43).

Dentro dessa ótica, a Educação Física tem um significado primordial dentro da Educação Básica, já que desenvolve o(a) aluno(a) como um todo, desde o âmbito motor e, acima desse, nos aspectos cognitivo, social e afetivo, desenvolvendo aspectos físicos e lógico-matemáticos, os quais serão utilizados por toda a vida, não dizendo, entretanto, que a Educação Física seja uma disciplina auxiliar das outras (FREIRE, 2011). Pereira et al (2019, p. 189) completam que a Educação Física "é uma disciplina necessária, que contribui para novas perspectivas de aprendizagem, indo além das práticas corporais, favorecendo o conhecimento, intermediado pela linguagem corporal e a cultura do corpo em movimento".

Logo, deve ser atribuída à Educação Física a devida importância no ambiente escolar, com o intuito de fomentar o desenvolvimento integral das crianças e adolescentes, pois, além de ter um propósito de formar futuros cidadãos e cidadãs ativos(as), deve, também, permitir que essas(es) discentes tenham uma aprendizagem e a consciência do próprio corpo.

\section{Metodologia}

O trabalho em questão trata-se de uma pesquisa qualitativa, tendo como investigados(as) exalunos(as) de uma Escola do distrito de Bentópolis - cidade de Ubaí, no Norte de Minas Gerais. A amostra é composta por11 (onze) ex-alunos(as), com idade entre 18 (dezoito) a 22 (vinte e dois) 
anos, formados(as) entre os anos de 2016 a 2019. Sendo esta pesquisa de análise qualitativa, não foi necessária uma quantidade expressiva de pesquisados(as), pois "a pesquisa qualitativa não se baseia no critério numérico para garantir sua representatividade" (MINAYO et. al, 2002, p.43). Para melhor compreensão, distribuímos os dados em uma tabela, como podemos ver a seguir:

\begin{tabular}{|c|c|c|}
\hline PÚBLICO & IDADE & ANO DE FORMAÇÃO \\
\hline Ex-aluna 1 & 21 & 2016 \\
\hline Ex-aluno 2 & 19 & 2019 \\
\hline Ex-aluna 3 & 19 & 2018 \\
\hline Ex-aluna 4 & 18 & 2019 \\
\hline Ex-aluno 5 & 18 & 2019 \\
\hline Ex-aluno 6 & 22 & 2017 \\
\hline Ex-aluna 7 & 18 & 2019 \\
\hline Ex-aluno 8 & 19 & 2019 \\
\hline Ex-aluno 9 & 19 & 2019 \\
\hline Ex-aluno 10 & 19 & 2018 \\
\hline Ex-aluno 11 & 21 & 2017 \\
\hline
\end{tabular}

Como recursos metodológicos, foram aplicados questionários on-line (Formulário Google), preparados pelas pesquisadoras, com 15 (quinze) perguntas, sendo 10 (dez) abertas e 5 (cinco) fechadas para as(os) pesquisadas(os). Após os resultados das respostas, disponibilizamos as mesmas em categorias, proposta por Minayo et al. (2002), que são empregadas para estabelecer classificações entre as respostas que possuem elementos ou características em comum. Com o intuito de esclarecer o objetivo do estudo, e solicitar autorização para a realização deste, o presente trabalho atende a todos os cuidados éticos previstos na Resolução 466/2012, tendo sido, portanto, solicitada aos participantes a autorização, por meio do TCLE (Termo de Consentimento Livre e Esclarecido), após submissão e aprovação do projeto pelo Comitê de Ética da instituição fomentadora da pesquisa.

\section{RESULTADO E DISCUSSÃO}

As categorias selecionadas para a discussão, após a coleta das respostas, foram as seguintes: conteúdos da Educação Física escolar; docentes da Educação Física escolar; a importância e o papel da Educação Física escolar.

\subsection{Conteúdos da Educação Física escolar}

No questionário, havia uma pergunta referente a quais foram os conteúdos/atividades que os(as) exalunos(as) tiveram em suas aulas de Educação Física escolar durante a Educação Básica. Pudemos perceber uma predominância de respostas referentes ao conteúdo Esporte - 8 (oito) das 11 (onze) respostas, sendo citado, principalmente, o futsal/futebol, como podemos ver nos exemplos das falas dos(as) Ex-alunos(as) 3, 5, 6 e 8, respectivamente: "em teoria quase nada, e [de] prática apenas futsal e pouquíssimas vezes vôlei"; "vôlei, futsal, basquete, alongamento, queimada"; "aula teórica, aula prática como futebol, basquete etc..."; "futsal".

A mesma realidade é possível observar em estudos como o de Sedorko e Finck (2016) que, após analisar as respostas obtidas pelos(as) alunos(as)dos anos finais do Ensino Fundamental de 3 (três) 
escolas da rede estadual de ensino do município de Ponta Grossa (Paraná), sobre a organização das aulas, atentou para a predominância do conteúdo Esporte. Esse cenário é notável há muito tempo, e foi constatado, também, por Finck (1995), bem como e nos estudos de Schneider e Bueno (2005, p. 31), em que as perguntas sobre o que mais era ensinado e aprendido nas aulas de Educação Física escolar, na rede pública da região da Grande Vitória-ES, tiveram como respostas mais frequentes "a aprendizagem dos esportes, suas regulamentações, os exercícios para aprendizagem e as regras de convivência que tais práticas proporcionam". Através disso, é possível perceber que essa hegemonia do conteúdo Esporte não é algo que surgiu há pouco tempo, mas uma realidade que vem sendo cultuada há alguns anos, e em diversos lugares.

No entanto, o que nos chamou a atenção, retratando uma possível modificação efetiva nas aulas de Educação Física dessa escola, é o fato do surgimento de respostas diferentes sobre outros conteúdos/atividades dos(as) ex-alunos(as) que se formaram no ano de 2019. Estes(as) trouxeram, dentre os conteúdos aplicados durante as aulas, além dos Esportes, os conteúdos de Dança e de Primeiros Socorros, como é possível observar nas respostas dos(das) Ex-alunos(as) 2, 4 e 7, respectivamente: "dança, música, primeiros socorros [sic] e esportes"; "aulas de primeiros socorros [sic], sobre handebol, voleibol, dança"; "futsal, peteca, xadrez, futebol, vôlei, atividades sobre primeiros socorros, atividades sobre ginástica, alongamentos e algumas brincadeiras".

Através das respostas acima descritas, e levando em consideração o ano de formação de todos(as) os(as) pesquisados(as), podemos notar que houve uma variedade maior de conteúdos citados por esses ex-alunos(as), especialmente pelos(as) alunos(as) formados(as) em 2019, em comparação aos estudantes dos nos anos anteriores, os quais citaram, basicamente, o Esporte, como podemos ver na declaração da Ex-aluna 1, formada no ano de 2016: "raras aulas teóricas e algumas aulas de vôlei, a maioria das vezes apenas o futsal". Isso nos leva a crer que houve uma mudança no ensino da Educação Física nessa escola, se comparamos com os outros anos, tendo em vista as respostas dos(as) pesquisados(as), caracterizando uma maior diversificação de conteúdos/atividades. Consideramos que tal fato possa resultar em um maior interesse dos(as) alunos(as) pelas aulas e uma possível identificação com as práticas corporais fora da escola, como afirmam Souza Júnior e Darido (2012, p. 56).

A fim de facilitar a adesão dos alunos às práticas corporais seria importante diversificar as vivências experimentadas nas aulas, para além dos esportes tradicionais (futebol, voleibol ou basquetebol). Na verdade, a inclusão e a possibilidade das vivências das ginásticas, dos jogos, das brincadeiras, das lutas, das danças podem facilitar a adesão do aluno na medida em que aumentam as chances de uma possível identificação.

Ao indagarmos se esses(as) ex-alunos(as) acreditam que os conteúdos que tiveram na Educação Física escolar foram importantes para sua formação, percebemos que 9 (nove) dos(as) 11 (onze) exdiscentes responderam que sim, ou seja, a maioria. Isso se deve a vários motivos, como podemos ver na falada da Ex-aluna 4: "sim, porque pude ter conhecimento de alguns conteúdos que talvez não me interessaria, mais[sic], que hoje eu acho muito importante". Destacamos, também, a resposta do Ex-aluno 10: "sim, pois trabalhou com conteúdos dinâmicos, nos dando conhecimento básico e trouxe alguns acontecimentos para que possamos ter experiências reais". Tivemos, ainda, justificativas relacionadas ao conhecimento sobre coisas em geral, do dia a dia, conhecimento sobre o corpo, conhecimento sobre diversos esportes, e para se desenvolver psicologicamente, como vimos nas falas dos(as) Ex-alunos(as) 2, 6, 7, 5 e 9. 
Segundo Pizaniet al (2016, p. 260), a "educação física como componente curricular da escola necessita ser provocadora de desejos, despertar nos alunos o interesse em aprender". De acordo com isso, e analisando as respostas, é possível perceber que a Educação Física, através de práticas voltadas para a realidade do dia a dia, pode vir a despertar nos(as) alunos(as) o interesse pelo seu conteúdo curricular e pelos conhecimentos/saberes nele presentes. Os(as) mesmos(as) autores(as)citados(as) anteriormente completam, ainda, que as aulas de Educação Física necessitam ter um ótimo nível de desafios, para não provocar a frustração e o desinteresse nos(as) discentes (PIZANI et al, 2016). Com isso, percebemos, mais uma vez na nossa pesquisa, que a diversidade de conteúdos provoca maiores níveis de interesse nos(as) alunos(as) pelas aulas, sendo cada vez mais importante para a sua formação.

Acreditamos que, por este motivo, a resposta sobre a variação dos conteúdos da Educação Física durante a vida escolar desses(as) ex-alunos(as), possibilitou a 6 (seis) deles(as), a maioria, responderem que não achavam que deveriam ter tido outros conteúdos abordados durante essas aulas. Essas respostas podem ser atreladas ao fato de muitos(as) discentes não terem uma visão abrangente de quais conteúdos/atividades devem ser estudados(as) de fato. Apesar da variedade de conteúdos apontados, como analisamos nos currículos vigentes da Educação Física, no período em que os(as) pesquisados(as) eram estudantes, existiam vários outros conteúdos, além dos citados, para serem aplicados, como: Conhecimentos Sobre o Corpo, outros Esportes, diferentes tipos de Jogos, Lutas e Ginásticas, assim como outras Danças e Atividades Rítmicas e Expressivas (BRASIL, 1997b; SEE, 2014a).

No entanto, algo que chama a atenção são as falas das Ex-alunas 1 e 3, respectivamente: "diferentes esportes, como o handebol, xadrez, e aulas teóricas com mais entusiasmo"; "mais aulas teóricas para entender sobre os fundamentos da ed. física que são muito abrangentes [sic] e aulas práticas que atendessem a ambos os sexos juntos! desconsiderando o futsal de sempre". Vários pontos são notáveis nessas respostas, principalmente o fato de almejarem aulas teóricas para um maior aprofundamento da disciplina. Todavia, no ensino da Educação Física escolar é essencial que tenha sempre a teoria ligada à prática, buscando a interação com o(a) aluno(a), por meio de discussões e reflexões, não necessitando que seja uma aula em sala para que seja teórica, mas que tenha esse cunho reflexivo, pensando, também, nos objetivos "atitudinais e conceituais, para além dos "procedimentais", reforçando alguns objetivos já trazidos pelos PCN (BRASIL, 1997a; BRASIL, 1997b; BRASIL, 1998). Com relação a esse aspecto, o CBC do Ensino Fundamental e do Ensino Médio salienta:

Integração teoria-prática - É importante ressaltar que os conhecimentos, no ensino da Educação Física, sejam analisados e contextualizados de modo a formar uma rede de significados de modo tal que os alunos possam perceber e compreender sua pertinência, bem como a relevância de sua aplicação na sua vida pessoal e social. Isso, por sua vez, demanda a criação de estratégias metodológicas que estimulem o aluno a apreender o conhecimento pelo processo de ação-reflexão-ação, ou seja, toda sistematização teórica deverá estar articulada com o fazer e todo fazer articulado com a reflexão (SEE, 2005, p. 25).

Encerramos essa categoria, alertando e fomentando a diversidade de conteúdos durante as aulas de Educação Física, mostrando, também, como esses conhecimentos podem repercutir de forma positiva nesses(as) educandos(as). Diante disso, ressaltamos a importância de aulas igualitárias para meninos e meninas, e como estas irão ajudar a estimular ações respeitosas entre os diferentes gêneros, bem como a se respeitarem e terem melhores relações interpessoais. 


\subsection{Docentes da Educação Física Escolar}

Como visto, o papel docente é importante para o processo pedagógico, cabe ao educador e à educadora aguçar a curiosidade desses(as) alunos(as) para o conhecimento (HAIDT, 1994). A fim de investigarmos sobre os(as) professores(as), da escola em questão, na pergunta 9 (nove), indagamos aos ex-alunos e ex-alunas como eles(as) definem a postura de suas(seus) professoras e/ou professores de Educação Física durante a e Educação Básica. No que diz respeito a essa pergunta, apenas as Ex-alunas 1 e 3 deram respostas que apresentam perspectivas negativas no que tange à prática pedagógica dos professores, como podemos ver, respectivamente: "alguns foram falhos. Era sempre as mesmas atividades e quase nunca participavam"; "não me acrescentaram nada, pois o empenho era muito pouco da parte deles". De acordo com Pizani et al. (2016), o professor e a professora de Educação Física desempenham um papel fundamental na motivação dos(as) alunos e alunas, pois a partir de incentivos em aula é que esses(as) alunos e alunas se sentem mais motivados(as) a aprender. Pereira et al (2019) corroboram esse conceito, tendo em vista seus estudos, nos quais puderam perceber que a porcentagem de alunos e alunas motivados pelos(as) professores(as) de Educação Física é a mesma dos(as) que se sentem desmotivados(as) (35,7\%); e atrelaram essa desmotivação à falta de exigências e interesse com os(as) discentes. A partir das falas das Ex-alunas, e da literatura citada, é possível interpretar que o empenho e entusiasmo, como dito, influenciou diretamente no interesse que os(as) alunos(as) vieram a ter por esse componente curricular.

Entretanto, 9(nove) dos(as) ex-alunos e ex-alunas deram respostas positivas, ou seja, a grande maioria dos(as) pesquisados(as), como podemos ver nos exemplos das falas dos(as) Ex-alunos(as) 4, 6 e 9, respectivamente: "uma postura de um professor que incentiva a aluna a fazer a prática de um esporte que ele julgava chato. Mostrar para os alunos que eles podem usufruir dos momentos das aulas, mais sem esquecer que estão em um ambiente de aprendizagem"; "bons, porque foram professores que sempre teve [sic] uma dedicação ao trabalho e a forma em que ajudava [sic] cada um de nós"; "são ótimos profissionais, explica [sic] bem a matéria se preocupa [sic] muito com seus alunos..." A partir dessas falas podemos perceber, mais uma vez, na nossa pesquisa, a importância do papel do professor e da professora na prática dos(as)discentes. Observamos, também, como esses(as) ex-alunos(as) enxergam essa preocupação e o cuidado dos(as) professores(as) de Educação Física que tiveram durante seu período de formação escolar.

Sobre isso, Souza e Paixão (2015) demonstram, com os resultados de sua pesquisa com alunos e alunas de $3^{\circ}$ (terceiro) ano do Ensino Médio de duas escolas públicas das cidades de Ouro Preto e Mariana (no estado de Minas Gerais), que a maior parte dos(as) estudantes definiram como "melhor" professor(a), aqueles(as) cuja dimensão humanista é evidenciada. Isto é, aqueles(as) docentes que possuem maiores relações interpessoais com os(as) discentes. Os mesmos autores ainda completam:

Essa situação pode ser explicada, nomeadamente, pela especificidade da Educação Física, que se configura como uma prática social e de intervenção e que se efetiva em ambientes que distam da sala de aula, como quadras, ginásios e espaços ao ar livre. Alguns professores afirmaram ter uma grande proximidade com os alunos, o que, por vezes, abre espaço para discutir temas relacionados a comportamento, valores éticos e conduta respeitosa, colaborativa e solidária dentro e fora do ambiente escolar. Em outras palavras, as relações interpessoais presentes no processo ensinoaprendizagem, sob os matizes de uma dimensão humanista, podem se configurar como tempo e lugar para o desenvolvimento de qualidades humanas básicas para a vida contemporânea. Ainda que essa especificidade possa, por um lado, representar um aspecto positivo no processo de ensino-aprendizagem, por outro, precisa ser bem 
conduzida pelo professor, para que as aulas de Educação Física não sejam entendidas como mero momento de descontração e possibilidade de ócio (SOUZA; PAIXÃO, 2015, p. 410).

No entanto, uma das respostas que mais nos saltou aos olhos, foi a resposta da Ex-aluna 7, como vemos a seguir:

Boa, razoável e excelente. Durante minha jornada estudantil tive 4 professores(as) de educação física e 2 deles (as) na minha opinião não tinham muito desempenho/habilidade/profissionalismo, pois as vezes não dominavam a matéria até mesmo deixavam os alunos fazerem o que queriam na quadra enquanto mexia [ $\mathrm{sic}]$ no celular ou resolvia [sic]alguma outra coisa. Já os outros 2 tinham muita competência, dominavam a matéria e tinha [sic]muito interesse em ensinar, sendo assim bastante capacitados e ótimos profissionais. Porém, todos eram bastante gente boa $[\mathrm{sic}]$, criativos e tentavam desenvolver algo rs $\equiv[\mathrm{sic}]$.

A partir da fala dessa Ex-aluna, podemos perceber a diferença entre professores(as) da Educação Básica, assim como em outras profissões, em que existem muitos(as) profissionais(as) competentes, comprometidos(as) e dedicados(as), como também alguns(as) que não possuem um desempenho equivalente, devido a vários motivos, os quaisnão serão nosso objeto de estudo neste trabalho. Inferimos, como uma possível justificativa para essa realidade, a Síndrome do Esgotamento Profissional (SEP), definida por Freudenberger (1974) apud Santini e Molina Neto (2005, p. 210),

[...] que a caracteriza como um sentimento crônico de desânimo, de apatia, de despersonalização que atinge 0 trabalhador. Para o autor, essa síndrome afeta principalmente os trabalhadores encarregados de cuidar, ou seja, pessoas que trabalham em contato direto com outras, entre os quais os médicos, os assistentes sociais, os psicólogos, os enfermeiros e os professores.

Assim, não podemos definir (e este não foi o objetivo desta pesquisa) o que pode trazer a apatia para os(as) professores(as) de Educação Física durante a sua prática docente, como citado por alguns(as) pesquisados(as). Porém, podemos afirmar que a forma como eles(as) atuam, ao longo da docência, influencia na percepção dos(as) alunos e alunas sobre eles(as) e o componente curricular em si, como pudemos observar nas respostas de todas(os) ex-alunos(as).

Um ponto positivo, para nós, da fala da Ex-aluna 7 é que ela não generaliza todos(as) os(as) docentes como profissionais que falharam na sua profissão, mas sim consegue definir separadamente que metade de seus(as) professores e professoras foram falhos, e que metade foram ótimos profissionais, cumprindo com seu papel social na vida dos(as) discentes. Tal fato revela indícios de que: mesmo a Educação Física tendo conteúdos específicos curriculares, o modo como estes chegam para os(as) educandos(as) está intrinsecamente ligado a como o docente se relaciona, não só com esses conteúdos, mas também com seus(suas) estudantes, durante a sua prática pedagógica.

\subsection{A importância e o papel da Educação Física escolar}

Esta categoria busca unir a percepção que viemos construindo do papel da Educação Física para esses(as) ex-escolares. Com isso, na pergunta 10 (dez), os(as) ex-alunos e ex-alunas foram questionados(as) sobre o que cada um(uma) entendia ser a Educação Física. Acerca dessa pergunta, tivemos 3 (três) respostas voltadas para a promoção da saúde: "uma atividade que ajuda as pessoas de várias formas como, manter-se em forma, condicionamento físico etc" (EX-ALUNO 8). "Uma matéria extraordinária porque ajuda todo mundo" (EX-ALUNO 9); também: "uma matéria de educação sobre o nosso corpo para que possa ter uma boa saúde" (EX-ALUNO 10). Essa mesma 
realidade aparece explicitamente nos estudos de Sedorko e Finck (2016) em que a grande maioria dos(as) alunos(as) pesquisados(as), 64,5\%, de 3 (três) escolas da rede pública estadual de ensino no município de Ponta Grossa-PR, relacionaram a importância da Educação Física aos conhecimentos difundidos sobre saúde. De acordo com esses(as) autores e autoras, e as respostas dos(as) ex-alunos e ex-alunas, podemos notar que essa visão, voltada para a área da saúde na Educação Física, ainda se encontra presente no meio escolar, e fora deste. Nesse sentido, somos conscientes de queque a Educação Física não possui, exclusivamente, esse cunho higienista, tendo, além de conteúdos voltados para os conhecimentos sobre o corpo e promoção da saúde, outros conteúdos, os quais estão relacionados à formação integral dos(as) alunos e alunas. Alertamos, também, que, pelos conteúdos atribuídos pelos(as) pesquisados(as) (majoritariamente o Esporte), interpretamos que a via (quase exclusiva), ensinada pelos(as) docentes em questão, era a prática de esportes, sem ampliar a possibilidade motora desses(as) alunos(as), até mesmo dentro de uma visão que enfatize o conceito de qualidade de vida.

Tivemos também 3 (três) definições voltadas para o Esporte, como podemos observar nas falas das Ex-alunas 1 e 4, e do Ex-aluno 11, respectivamente: "área de conhecimento que se pratica esportes corporais"; "Educação física para mim é uma área de conhecimento humano ligado a práticas de esportes"; "uma ciência que estuda os esportes e similares etc.". A partir dessas respostas, podemos notar uma grande influência do Esporte na definição de Educação Física escolar, até mesmo nos dias atuais. Após a Educação Física ser submetida a um cunho higienista, começou a ser vista de outra forma, como ressaltam González, Fensterseifer e Lemos (2007) apud Gonzalez e Fensterseifer (2009):a partir da metade do século passado, a Educação Física passou a ter uma relação tão forte com o Esporte, que acaba sendo confundida com essa prática, e esse fato passou a ser conhecido como a Esportivização da Educação Física. Por essas respostas, percebemos que essa ainda é uma realidade, o que pode causar um pré-conceito, e até a não aceitação por pessoas que não possuam afinidade com o Esporte.

Entendemos que o Esporte é importante para a Educação Física, mas reforçamos nosso alerta para não ser o único conteúdo atribuído à disciplina, considerando que este componente curricular possui diversos conteúdos, aqui já citados, que são tão relevantes quanto o Esporte; e que terão mais chances de agregar conhecimento e enriquecer o repertório motor, como também cultural, social, e os demais conhecimentos, dos(as) alunos e alunas.

Por conseguinte, tivemos, ainda, algumas definições interessantes da Educação Física, como observamos nas falas dos(as) Ex-alunos(as) 2, 5, 6 e 7, respectivamente: "conhecimento humano ligada às práticas corporais"; "são todos os exercícios físicos que você faz"; "pra [sic] mim educação física é o conhecimento do corpo, pelo fato de ter bastante movimento com o corpo"; "é um conjunto de práticas de exercícios e atividades físicas, que envolve não somente o corpo mas também a mente, sendo muito importante e essencial para todas as pessoas". De acordo com essas afirmações, notamos que 4(quatro) dos(as) ex-alunos(as) pesquisados(as) possuem uma visão mais abrangente e próxima do que realmente é a Educação Física escolar. Entretanto, uma das respostas que consideramos mais interessante foi a da Ex-aluna 3: "educação física é uma forma de conhecermos um pouco sobre o funcionamento do nosso corpo, e aprendermos a nós [sic] cuidar..., praticando esportes, atividades físicas..., tornando-as prazerosas e inclusivas ao nosso dia a dia!"

Diante do exposto, atentamos para uma análise positiva da Educação Física escolar na vida dessa exaluna, pois percebemos que ela parece possuir uma compreensão mais ampla sobre o que é a 
Educação Física escolar, sendo este um reflexo de como esta foi desenvolvida com o passar dos anos. Podemos perceber, também, que essa ex-aluna entende que este componente curricular possui um papel pedagógico, e que seus conteúdos, sejam eles práticos ou teóricos, ou seja, procedimentais, conceituais e atitudinais (BRASIL, 1997a; BRASIL, 1997b; BRASIL, 1998), devem estar inclusos no dia a dia dos(as) alunos e alunas, e precisam ter sentidos e significados para a vida. Então, através deste relato, é possível analisar que a Educação Física também é considerada como um componente educacional, isto é: ensina questões que vão além de gestos motores específicos.

Na pergunta 11 (onze), questionamos os(as) ex-alunos(as) se eles teriam sentido falta, caso não tivessem aula de Educação Física na escola. Para essa pergunta, obtivemos respostas distintas. Dentre elas, apenas uma resposta que consideramos negativa, da Ex-aluna 3, como podemos ver na sua declaração: "não. por que [sic] definitivamente não me acrescentou nada...". Obtivemos, também, as seguintes respostas: "sim, porque praticar esportes, fazer exercício na escola acabou ajudando no meu desenvolvimento, e também na minha escolha para o meu futuro" (EX-ALUNA 4); "sim, porque educação física sempre foi a melhor aula e ajudou muito a mim pelo fato de gosta de esportes" (EX-ALUNO 6).

Analisando esses relatos, é possível reforçar como esses(as) ex-alunos e ex-alunas relacionam a importância das aulas de Educação Física à prática de esportes. Podemos, a partir das respostas dos(as) ex-discentes, concordar com a literatura estuda da (SEDORKO; FINCK, 2016; FINK, 1995; SCHNEIDER, BUENO, 2005), pois a relação que os(as) ex-alunos(as) fazem da Educação Física escolar aos esportes, tende a ser resultado das metodologias estudadas e dos conteúdos aplicados pelos(as) professores e professoras. Em conformidade a isso, acreditamos que os(as) alunos e alunas saiam prejudicados(as), uma vez que a priorização de alguns conteúdos em detrimento de outros (sendo ele o Esporte ou não), interferirá nas experiências vivenciadas por eles(elas), refletindo negativamente na sua formação, tanto em seu repertório motor quanto em outros aspectos, como nas relações interpessoais. Sendo assim, impedem o acesso ao que é direito dos estudantes: o acervo da cultura corporal, cuja responsabilidade é do(a) professor(a) de Educação Física.

Destacamos outras respostas sobre a ausência da disciplina na escola, as quais nos remetem à ideia de que os(as) ex-alunos(as) atribuem a importância das aulas de Educação Física a um momento unicamente de distração, como é possível depreender com as falas dos(as) Ex-alunos(as) 1, 2 e 5 respectivamente: "Sim. Pois foi uma forma de distração"; "muita. São mais divertida"; "sim, era a única coisa que me divertia". No nosso referencial teórico, já havíamos citado resultados como esse, nos estudos de Brandolin, Koslinsk e Soares (2015). A partir disso, nota-se que alguns(as) ex-alunos e ex-alunas relacionam o tempo das aulas de Educação Física com um período para ficarem ociosos(as). Não visualizam a Educação Física como um componente curricular que em seu tempo de aula precisa ter objetivos claros.

Todavia, a maioria dos(as) ex-alunos e ex-alunas - 5 (cinco) deles, deram declarações que enxergamos como positivas, como observado nas falas dos(as) ex-estudantes):"Sim, pois através dela a gente se enturma com mais facilidade, pratica atividades e exercícios físicos que ajuda a relaxar o corpo e a mente e as brincadeiras também são de grande importância" (EX-ALUNA 7); "sim" (EXALUNO 8); "porque eu não teria o mesmo desempenho agilidade e a educação que tenho hoje" (EXALUNO 9); "sim. Não que seja apenas um momento de descontração muitas das vezes, mas também por trabalhar em conjunto de uma maneira mais descontraída possibilitando um aproximamento [sic] de muitos outros colegas" (EX-ALUNO 10). Evidenciamos, também, a afirmação do Ex-aluno 11: "Sim. 
Era uma das matérias que mais gostava, principalmente pela existência de aulas dinâmicas diferente de todas as outras matérias".

A Educação Física escolar possui características positivas para o seu desenvolvimento, como, por exemplo, o espaço onde geralmente acontecem e utilizados e a aplicação da prática corporal, sendo uma especificidade da área, e a distinguindo das demais disciplinas curriculares (SOUZA; PAIXÃO, 2015). O autor e a autora Santos e Maximiano (2013) fortalecem essa concepção, já que, segundo eles, a Educação Física não é uma disciplina como as demais, visto que valorizam outras relações com o saber se comparada às outras. A partir das respostas dos(as) ex-alunos e ex-alunas, e da literatura analisada, depreendemos que a Educação Física possui características que se torna um diferencial, dentre elas, a de ter outros ambientes para a sua prática e por usar o corpo em movimento. Com isso, existe mais possibilidades de interação entre os(as) alunos e alunas e, também, entre professores(as) e alunos(as), podendo, dessa maneira, existir um trabalho mais dinâmico e atrativo, não deixando de lado a parte principal, que é o pedagógico.

Por fim, considerando a última pergunta, todos e todas os(as) ex-alunos e ex-alunas - os(as) 11 (onze), consideram a Educação Física uma disciplina escolar. Dentre todas as respostas positivas, apresentamos duas que acreditamos serem importantes: "Sim. Tão importante quanto qualquer outra matéria" (EX-ALUNA 1). Essa resposta vai ao encontro do que já levantamos nesse trabalho: que a Educação Física escolar, mesmo sendo uma disciplina diferente das demais, por utilizar dos movimentos corporais e do lúdico (SANTOS; MAXIMILIANO, 2013), é uma disciplina que pode vir a ter uma grande relevância na vida dos(as) alunos e alunas, como qualquer outra disciplina. Como exemplo, destacamos uma das declarações da Ex-aluna 7, quando diz que esta é "uma disciplina essencial". Com isso, interpretamos que a Educação Física, mesmo não sendo entendida da mesma forma, em sua totalidade, por todos(as) os(as) alunos e alunas, foi de grande relevância na vida dos(as) ex-alunos e ex-alunas, e é considerada por todos(as) como um componente curricular expressivo.

\section{CONSIDERAÇÕES}

Nesta pesquisa, observamos importantes diferenças nas respostas correspondentes ao último ano pesquisado (2019) em relação ao primeiro ano (2016). Concluímos que houve uma "melhora" no ensino da Educação Física na escola pesquisada, e que esses(as) ex-alunos e ex-alunas possuem uma percepção mais coerente do que é essa disciplina. Através do olhar destes ex-discentes, averiguamos como a postura do(a) professor(a) de Educação Física pode influenciar na percepção do componente como um todo. Por isso, salientamos a importância de um ensinar pedagógico comprometido, tendo responsabilidade docente durante o processo de ensino. Ressaltamos, nesse sentido, a importância da diversidade de conteúdos durante as aulas de Educação Física escolar, pois isso irá influenciar de forma positiva nos conhecimentos absorvidos pelos(as) alunos e alunas durante o período escolar, além de terem maiores experiências, um repertório motor, cultural e social enriquecido, proporcionando maior interesse pelas aulas.

Com isso, salientamos, mais uma vez, que a diversificação de conteúdos e a postura do(a) professor(a) é de suma importância para atrair a atenção e o interesse dos(as) alunos e alunas pelas aulas. Reforçamos, ainda, que apercepção dos(as) alunos(as) é que definirá a legitimação dessa disciplina no meio e, portanto, a legitimação depende de como esta vem sendo trabalhada. Ademais, alertamos que os(as) professores(as) devem estar atentos(as) a desenvolverem uma diversidade de 
conteúdos possíveis e com um intuito pedagógico, pois a Educação Física é uma disciplina rica em assuntos e, quando os(as) discentes ficam restritos apenas a alguns (sejam eles esportes ou qualquer outro conteúdo), estão privando seus(suas) alunos(as) de desenvolverem mais possibilidades físicas, cognitivas e sociais. Os/As estudantes estão sendo privados de conhecer e experimentar a cultura corporal em toda a sua amplitude e diversidade.

Enfatizamos que a Educação Física escolar possui um diferencial na sua execução, uma vez que, além de utilizar o movimento como instrumento base de ensino, ainda usa diferentes espaços físicos e metodologias, que podem vir a ser muito atraentes para os(as) discentes e, por isso, obter maior interesse por parte deles(as), sendo essa uma forma mais fácil de desenvolver todos os conteúdos previstos em lei.

Finalmente, refletimos e acreditamos que um caminho frutífero para a importância da Educação Física na Educação Básica reside na diversificação e na melhor aplicação dos conteúdos, assim como defendemos que os(as) professores(as) sejam empenhados(as), e que tenham estrutura para desenvolverem melhor seu conhecimento científico, pois somente dessa fora os(as) alunos e alunas terão uma percepção mais abrangente da Educação Física escolar. Para auxiliar nessa diversificação de conteúdos e de possibilidades para a prática pedagógica, sugerimos que as secretarias de educação priorizem as condições de trabalho dignas para esses(as) docentes, como também invistam em formação continuada para estimular os(as) professores(as) a se atualizarem constantemente.

\section{REFERÊNCIAS}

MEDINA, João Paulo Subirá. A Educação Física cuida do corpo... e "mente". Campinas: Papirus, 1983. p. 99 - 105.

BRANDOLIN, Fábio; KOSLINSKI, Mariane Campelo.; SOARES, Antônio Jorge Gonçalves. A percepção dos alunos sobre a Educação Física no Ensino Médio. Revista de Educação Física, v. 26, n. 4, p. 601-610, 4. trim., 2015. Disponível em: < https://www.scielo.br/pdf/refuem/v26n4/1983-3083refuem-26-04-00601.pdf> Acesso em 29 mar 2021.

BRASIL. Base Nacional Comum Curricular: Educação é a Base. Brasília: MEC/Secretaria de Educação Básica, 2018.

BRASIL. Ministério da Educação. Parâmetros curriculares nacionais: Ensino Médio. Brasília: MEC/SEMTC, 1999.

BRASIL. Secretaria de Educação Fundamental. Parâmetros curriculares nacionais: introdução aos parâmetros curriculares nacionais / Secretaria de Educação Fundamental. Brasília: MEC/SEF, 1997 a.

BRASIL. Secretaria de Educação Fundamental. Parâmetros curriculares nacionais: Educação física / Secretaria de Educação Fundamental. Brasília: MEC/SEF, 1997 b.

BRASIL. Secretaria de Educação Fundamental. Parâmetros curriculares nacionais: Educação Física / Secretaria de Educação Fundamental. Brasília: MEC / SEF, 1998.

CAUM, Catarine; GALIETA, Tatiana. O "Conteúdo Básico Comum": uma análise linguística da Proposta Curricular de Minas Gerais. R. B. E. C. T., v. 5, n. 3, set-dez., 2012. Disponível em: < https://periodicos.utfpr.edu.br/rbect/article/view/1384/899> Acesso em 29 mar 2021. 
DARIDO, Suraya Cristina. Educação física na escola: conteúdos, suas dimensões e significados. Universidade Estadual Paulista. Prograd. Caderno de formação: formação de professores didática geral. São Paulo: Cultura Acadêmica, p. 51-75, 2012.

DARIDO, Suraya Cristina; SOUZA JÚNIOR, Osmar Moreira de. Para ensinar educação física: possibilidades de intervenção na escola. Campinas-SP: Papirus, 2007.

DEZANI, Gabriel Santos; MANZANO, Leonardo Alfonso; PAGANI, Mario Mecenas; ANDRADE, Viviane Aires de. A importância das aulas de Educação Física no Ensino Infantil. Revista Cientifica da Faculdade de Educação e Meio Ambiente. v.5, n.2, p.115- 124, jul|dez, 2014. Disponível em: < http://www.faema.edu.br/revistas/index.php/Revista-FAEMA/article/view/234/374> Acesso em 29 mar 2021

FINCK, Silvia Christina Madrid. Educação Física e Esporte: uma visão na escola pública.

[Dissertação de Mestrado em Educação). Piracicaba: Universidade Metodista de Piracicaba; 1995.

FREIRE, João Batista. Educação de corpo inteiro: teoria e prática da educação física / João Batista Freire. - 1. ed. - São Paulo: Scipione, 2011.

GONZÁLEZ, Fernando Jaime. Atuação dos professores na educação física escolar: entre o abandono do trabalho docente e a renovação pedagógica. In: SILVA, Paula Cristina e colaboradores (Org.). Territorialidade e diversidade regional no Brasil e América Latina: suas conexões com a educação física e as ciências do esporte. Florianópolis, SC: Tribo da Ilha, 2016. p. 45-70.

GONZALEZ, Fernando Jaime; FENSTERSEIFER, Paulo Evaldo. Entre o "não mais" e o "ainda não": pensando saídas do não lugar da educação física escolar I. Cadernos de Formação RBCE, p. 924, setembro 2009. Disponível em: < http://revista.cbce.org.br/index.php/cadernos/article/view/929/539> Acesso em 29 mar 2021.

HAIDT, Regina Célia. Curso de Didática Geral. São Paulo: ática, 1994. 327p.

LAVOURA, Tiago Nicola; BOTURA, Henrique Moura Leite; DARIDO, Suraya Cristina. Educação física escolar: conhecimentos necessários para a prática pedagógica. Revista da Educação

Física/UEM, Maringá, v. 17, n.2, p.203-209, 2006. Disponível em: <

https://periodicos.uem.br/ojs/index.php/RevEducFis/article/view/3341/2414> Acesso em 29 mar 2021.

MELO, José Pereira de. Perspectivas da educação física escolar: reflexão sobre a educação física como componente curricular. Revista Brasileira de Educação Física e Esporte, São Paulo, v.20, p. 188-190, sup. 5. setembro, 2006. Disponível em: < http://citrus.uspnet.usp.br/eef/uploads/arquivo/53_Anais_p188.pdf> Acesso em 29 mar 2021.

MINAYO, Maria Cecília de Souza (Org.) et. al. Pesquisa Social: Teoria, método e criatividade. $21^{\text {a }}$ ed. Petrópolis: Vozes, 2002.

MOURA, Diego Luz; COSTA, Kamilla Ribeiro Nunes; ANTUNES, Marcelo Moreira. Educação Física e Educação Infantil: uma análise em seis periódicos nacionais. Pensar a Prática, Goiânia, v. 19, n.1, p. 182-195, jan./mar. 2016. Disponível em: < https://www.revistas.ufg.br/fef/article/view/34061/pdf> Acesso em 29 mar 2021.

MOURA, Jeane Karine Silva; SOUZA, Ézio José Silva; CARVALHO, Rayane Crystine Nascimento. A importância das Práticas Pedagógicas na construção de limites durante o processo de formação humana da criança na escola. In: Fórum Internacional de Pedagogia, 4., 2012, Parnaíba. Anais... Campina Grande: Realize Editora, 2012.

PEREIRA, Cássia Juliane Pinto; NIZA, Iara Fernanda Dias; TEIXEIRA, Jeisabelly Adrianne Lima; COSTA, Aline Marques da; SOUZA, Djalma Santos. Grau de satisfação dos alunos nas aulas de 
Educação Física no Ensino Médio das Escolas Estaduais da Cidade de Monte Azul-MG. Revista Psicologia \& Saberes, v. 8, n. 11, p. 188-200, 2019. Disponível em: <

https://revistas.cesmac.edu.br/index.php/psicologia/article/view/979> Acesso em 29 mar 2021.

PINTO, José Alberto; CUNHA, Flávio Henrique Gomes. O tênis como alternativa no currículo escolar para crianças entre 8 e 12 anos. Motriz, v.4, n.1, p.26-34, 1998. Disponível em: < https://www.periodicos.rc.biblioteca.unesp.br/index.php/motriz/article/view/6584> Acesso em 29 mar 2021.

PIZANI, Juliana; BARBOSA-RINALDI, Ieda Parra; MIRANDA, Antonio Carlos Monteiro de; VIEIRA, Lenamar Fiorese. (Des) motivação na educação física escolar: uma análise a partir da teoria da autodeterminação. Revista brasileira de ciências do esporte, v. 38, n. 3, p. 259-266, 2016. Disponível em: https://www.scielo.br/pdf/rbce/v38n3/0101-3289-rbce-38-03-0259.pdf Acesso em 29 mar 2021.

SANTINI, Joarez; MOLINA NETO, Vicente. A síndrome do esgotamento profissional em professores de educação física: um estudo na rede municipal de ensino de Porto Alegre. Revista Brasileira de Educação Física e Esporte, v. 19, n. 3, p. 209-222, 2005. Disponível em: < http://www.revistas.usp.br/rbefe/article/view/16596/18309> Acesso em 29 mar 2021.

SANTOS, Wagner dos; MAXIMIANO, Franciele de Lima. Memórias discentes em educação física na educação básica: práticas avaliativas. Movimento, Porto Alegre, v. 19, n. 2, p. 79-101, abr./jun. 2013. Disponível em: < https://seer.ufrgs.br/Movimento/article/view/31062/25255> Acesso em 29 mar 2021.

SEDORKO, Clóvis Marcelo; FINCK, Silvia Christina Madrid. Sentidos e significados do esporte no contexto da Educação Física escolar. Journal of Physical Education, v. 27, 2016. Disponível em: < https://www.scielo.br/pdf/jpe/v27/2448-2455-jpe-27-e2745.pdf> Acesso em 29 mar 2021.

SEE. Secretaria de Estado de Educação de Minas Gerais. Currículo Básico Comum de Educação Física Ensino Fundamental, Ano Iniciais: Ciclos de Alfabetização e Complementar. Revisão. Belo Horizonte: SEE, 258 p. 2014 a.

SEE. Secretaria de Estado de Educação de Minas Gerais. Currículo Básico Comum de Educação Física Ensino Fundamental, Ano Finais: Ciclos Intermediário e da Consolidação. Revisão. Belo Horizonte: SEE, 65 p. 2014 b.

SEE. Secretaria de Estado de Educação de Minas Gerais. Currículo Básico Comum de Educação Física - Ensino Fundamental e Médio. Belo Horizonte: SEE, 68 p. 2005.

SCHNEIDER, Omar; BUENO, José Geraldo Silveira. A relação dos alunos com o saber compartilhado nas aulas de educação física. Movimento, Porto Alegre, v. 11, n. 3, jan./abr. 2005. Disponível em: < https://www.scielo.br/pdf/jpe/v27/2448-2455-jpe-27-e2737.pdf> Acesso em 29 mar 2021.

SOUZA, Jaqueline Aparecida de; PAIXÃO, Jairo Antônio da. A prática do bom professor de Educação Física na perspectiva dos alunos do Ensino Médio. Revista brasileira de estudos pedagógicos, v. 96 , n. 243, p. 399-415, 2015. Disponível em: < https://www.scielo.br/pdf/rbeped/v96n243/21766681-rbeped-96-243-00399.pdf> acesso em 29 mar 2021.

VEIGA, Ima Passos Alencastro. A Prática Pedagógica do professor de Didática. Ilma passos Alencastro Veiga. Campinas: Papirus, 1989.

Submissão: 24/01/2021

Aceito: 29/03/2021 